\title{
Diameter controlled growth of SWCNTs using Ru as catalyst precursors coupled with atomic hydrogen treatment
}

\author{
F.Z. Bouanis ${ }^{\mathrm{a}, \mathrm{b}, *}$, I. Florea $^{\mathrm{b}}$, M. Bouanis ${ }^{\mathrm{c}}$, D. Muller ${ }^{\mathrm{d}}$, A. Nyassi ${ }^{\mathrm{c}}$, F. Le Normand ${ }^{\mathrm{d}}$, D. Pribat ${ }^{\mathrm{b}, \mathrm{e}}$ \\ a University Paris Est, IFSTTAR, Boulevard Newton, 77420 Champs-sur-Marne, France \\ b Laboratory of Physics of Interfaces and Thin Films, UMR 7647 CNRS/Ecole Polytechnique, University Paris Saclay, 91128 Palaiseau Cedex, France \\ ${ }^{c}$ Laboratory of Catalysis and of Corrosion Materials (LCCM), Faculty of Sciences, University Chouaib Doukkali, B.P. 20, M-24000 El Jadida, Morocco \\ d ICube-Laboratory of Engineering, Computer Science and Imagery, University of Strasbourg-CNRS, 23, rue du Loess, 67037 Strasbourg Cedex, France \\ e Department of Energy Science, Sungkyunkwan University, Suwon, Republic of Korea
}

\section{G R A P H I C A L A B S T R A C T}

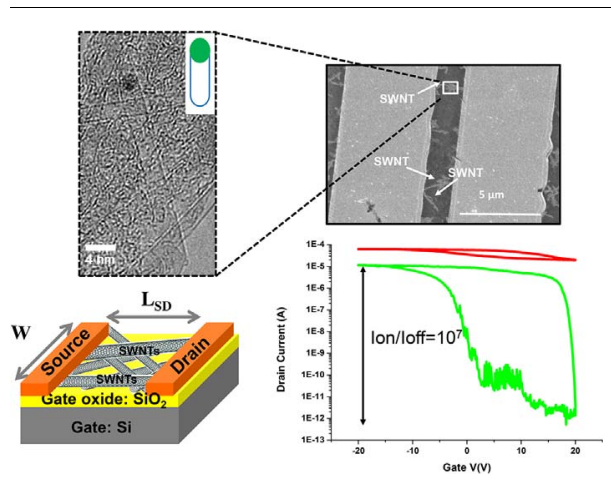

\section{A R T I C L E I N F O}

\section{Keywords:}

Single walled carbon nanotubes (SWCNTs)

Double hot filament chemical vapor deposition (d-HFCVD)

FIB

HR-TEM

Molecular beam epitaxy (MBE)

Field effect transistors (FETs)

\begin{abstract}
A B S T R A C T
In this work, we present a practical approach for controlling single walled carbon nanotubes (SWCNTs) diameter distribution through thin film $\mathrm{Ru}$ catalyst, coupled with hydrogen pre-treatment. Uniform and stable Ru nanoclusters were obtained after dewetting the Ru thin films under atomic hydrogen pre-treatment. SWCNTs were synthetized by double hot filament chemical vapor deposition (d-HFCVD) on $\mathrm{SiO}_{2} / \mathrm{Si}$ substrates at different temperatures. We found that the temperature is an important synthesis parameter that influences the diameter distribution of the final SWCNTs. Statistical analysis of the Raman radial breathing modes evidences the growth of highly enriched semi-conducting SWCNTs (about 90\%) with narrow diameter distribution that correlates directly with the catalyst particle size distribution. Electrical measurement results on as-grown SWCNTs show good thin-film transistor characteristics.
\end{abstract}

\section{Introduction}

Single walled carbon nanotubes (SWCNTs) have shown outstanding potential in nanoelectronics due to their exceptional properties such as high mobility, high current density, as well as good chemical and mechanical stabilities [1-3]. However, SWCNTs can be either metallic (m-SWCNTs) or semi- conducting (s-SWCNTs), depending on the tube diameter and chirality [4]. It is also well established that SWCNT-based electronic devices require the absence of metallic specimens (mSWCNTs) because they significantly degrade device performance [2].

\footnotetext{
* Corresponding author at: University Paris Est, IFSTTAR, Boulevard Newton, 77420 Champs-sur-Marne, France.

E-mail address: fatima.bouanis@ifsttar.fr (F.Z. Bouanis).
} 


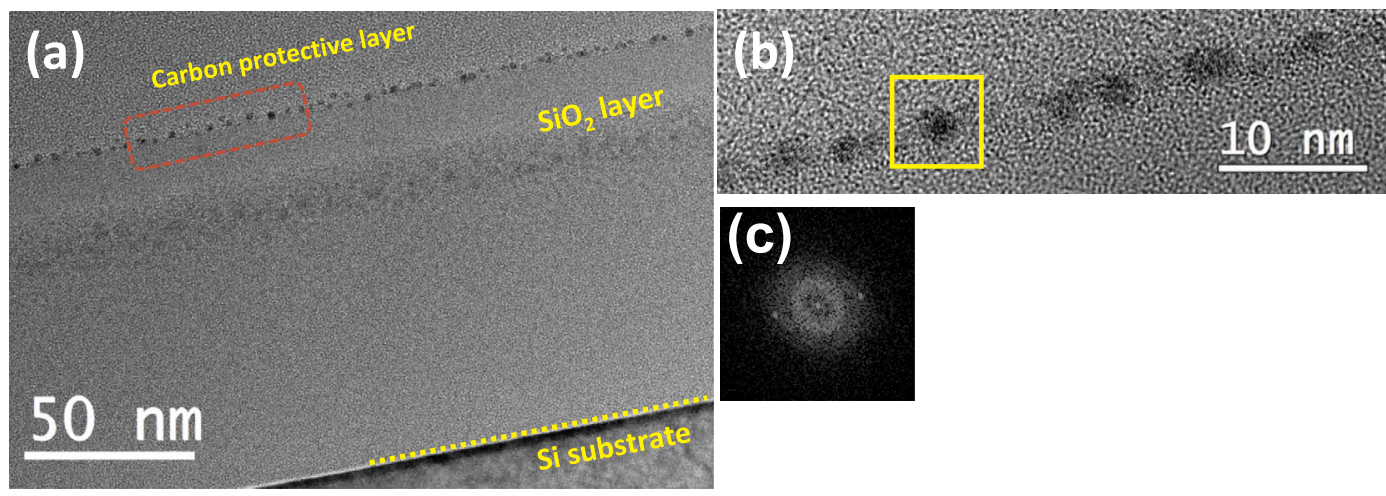

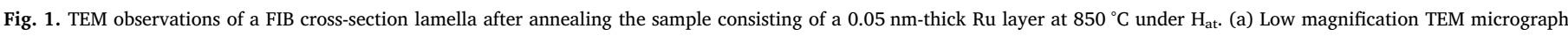

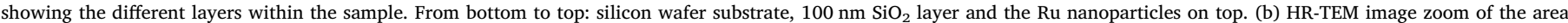
marked by the red rectangular in (a) showing the size of the particles. (c) Displays the FFT of the selected Ru nanoparticle (yellow square in b) and shows its crystalline character.
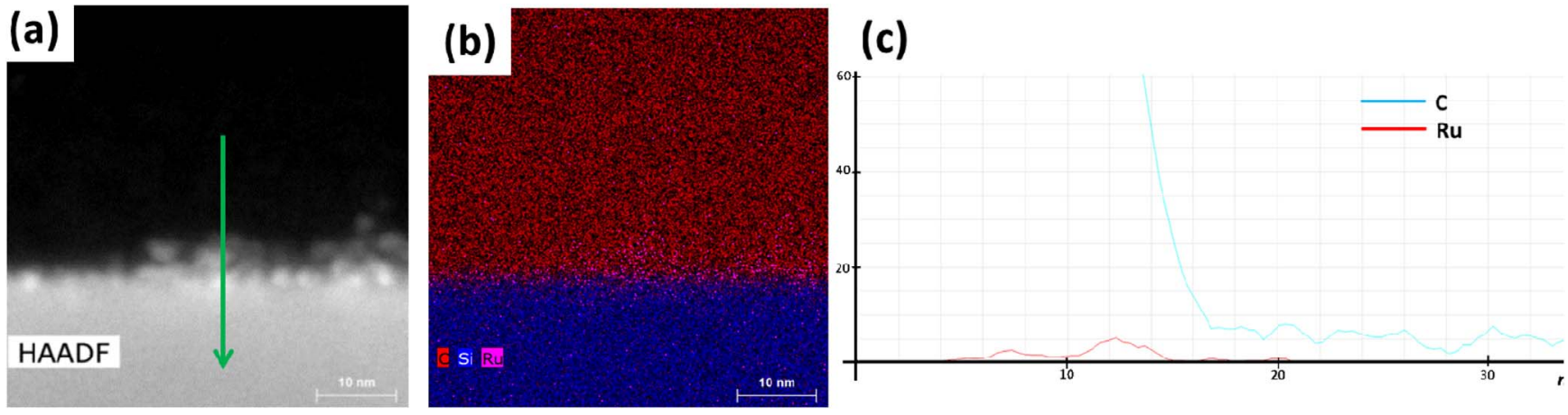

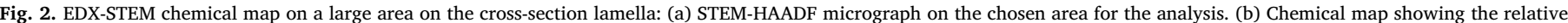

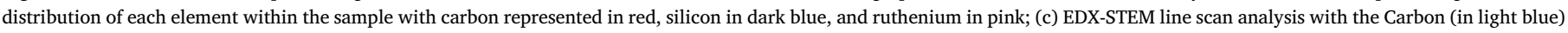
and Ruthenium (in red) concentrations recorded along the green line in (a).

Therefore, the synthesis of SWCNTs with well-controlled diameter and chirality is currently the biggest challenge for the SWCNTs community.

Significant research efforts have been dedicated to obtain SWCNTs with small diameters, as well as a narrow diameter distribution, using synthesis methods such as laser vaporization and arc-discharge [5]. Unfortunately, such methods are not suitable to produce SWCNTs on a large scale with a precise chirality $[5,6]$. Catalytic Chemical vapor deposition (C-CVD) is better suited for large scale synthesis and offers a better control over, e.g., SWCNTs diameters, by selecting and restraining a few reaction parameters [7]. During C-CVD, catalyst nanoparticles (usually metallic) help decompose the growth nutrient, which is a carbon-bearing gas such as methane $\left(\mathrm{CH}_{4}\right)$ diluted in hydrogen $\left(\mathrm{H}_{2}\right)$. The growth temperature, the flow rate of the gaseous growth nutrient, and the catalyst nature, structure and size [8-10] are some of the growth parameters that play a significant role in determining the properties of the nanotubes $[11,12]$. To date, the most successful way for synthesizing diameter-controlled SWCNTs by C-CVD method has been based on controlling the catalyst size.

In a recent publication [13], we have demonstrated the possibility to control the density and the size of the catalysts nanocluster by using a chemical approach for its preparation. Briefly, we used surface functionalization of the substrate, followed by grafting of a monolayer of metal salts or compounds coupled with an atomic hydrogen $\left(\mathrm{H}_{\mathrm{at}}\right)$ pre-treatment at high temperature, to decompose the metal salt or compound, yielding randomly distributed metal nanoclusters on the surface of the substrate. SWCNTs exhibiting remarkably good crystalline quality were obtained using this approach, with their diameter (and type) strongly dependent on the nature of the catalyst precursor and on its preparation.

In particular, we have observed that when ruthenium (Ru) nanoparticles (NPs) were obtained from the thermal decomposition of a self- assembled monolayer (SAM) of ruthenium porphyrin (RuTPP), the distribution of Ru NPs after decomposition was centered around $1.9 \mathrm{~nm}$ (80\%) and SWCNTs after growth were predominantly semiconducting. On the other hand, when Ru NPs were obtained from the decomposition of a ruthenium chloride $\left(\mathrm{RuCl}_{3}\right) \mathrm{SAM}$, the distribution of the Ru NPs after decomposition was broader, their diameter was larger (55\% of Ru nanoparticles were $2.8 \mathrm{~nm}$ in diameter) and SWCNTs after growth comprised many metallic specimens [13]. This result is quite interesting as it clearly confirms that the chirality of SWCNTs is not only determined by the chemical nature of the catalyst, but also by its size or crystalline orientation/structure. Of course, this implicitly assumes that the catalyst nanoparticles do not melt during the overall SWCNT growth process (i.e., for temperatures below $1000^{\circ} \mathrm{C}$ ), which is certainly the case with Ru whose melting temperature is $2334{ }^{\circ} \mathrm{C}$ (even if considering a depression of the melting temperature for nanosized particles).

In order to shed more light on the properties of Ru-catalyzed SWCNTs, we concentrate in the present study on SWCNTs properties obtained from Ru nanoparticles originating from the dewetting of a thin $\mathrm{Ru}$ film deposited by ultra-high vacuum evaporation in a molecular beam epitaxy (MBE) reactor. This is meant to replace a rather complex surface functionalization procedure (as in Ref. [13]) by a simpler thinfilm-like deposition step. We believe that the control of the diameter of SWCNTs is possible by preparing arrays of catalysts with a uniform size. Significant progress has been made here, to develop a practical approach, to control the diameter of SWCNTs and to better understand the relationship between the SWCNTs diameter and the catalyst diameter.

The SWCNTs were synthesized on $\mathrm{SiO}_{2} / \mathrm{Si}$ substrates from thin evaporated $\mathrm{Ru}$ films. Those $\mathrm{Ru}$ films were first dewetted at different temperatures $\left(800{ }^{\circ} \mathrm{C}, 850{ }^{\circ} \mathrm{C}, 900{ }^{\circ} \mathrm{C}\right.$ and $\left.950{ }^{\circ} \mathrm{C}\right)$ in order to produce arrays of randomly distributed Ru nanoparticles. Next, the effect of the 

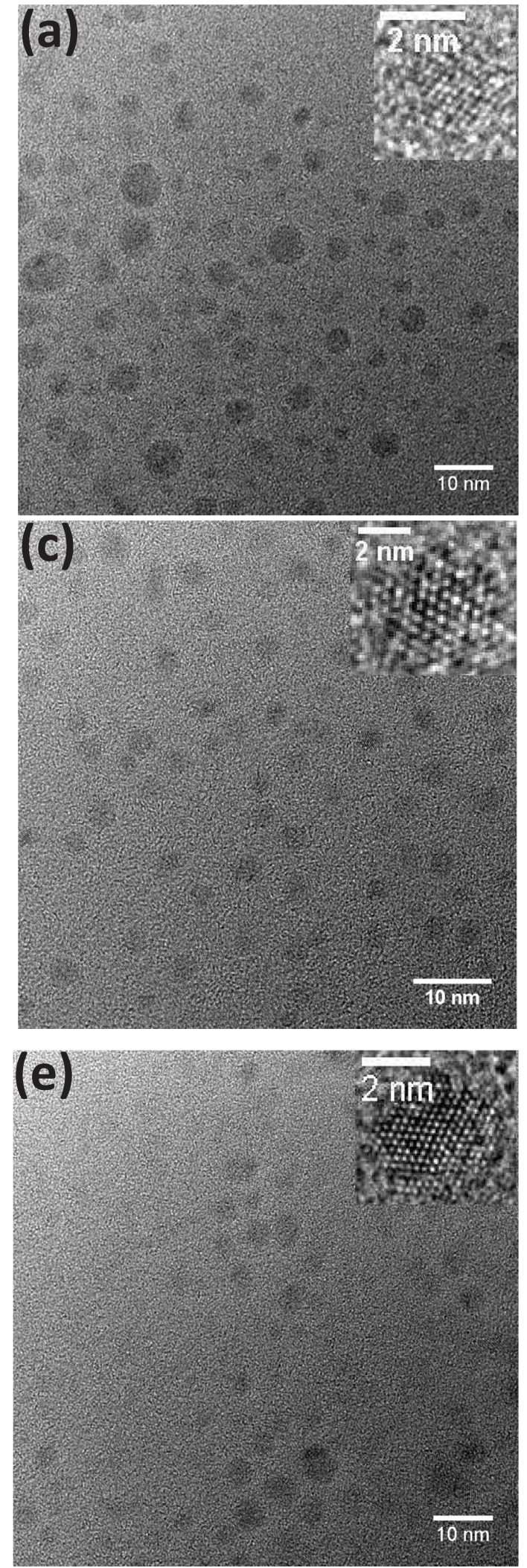

(b)

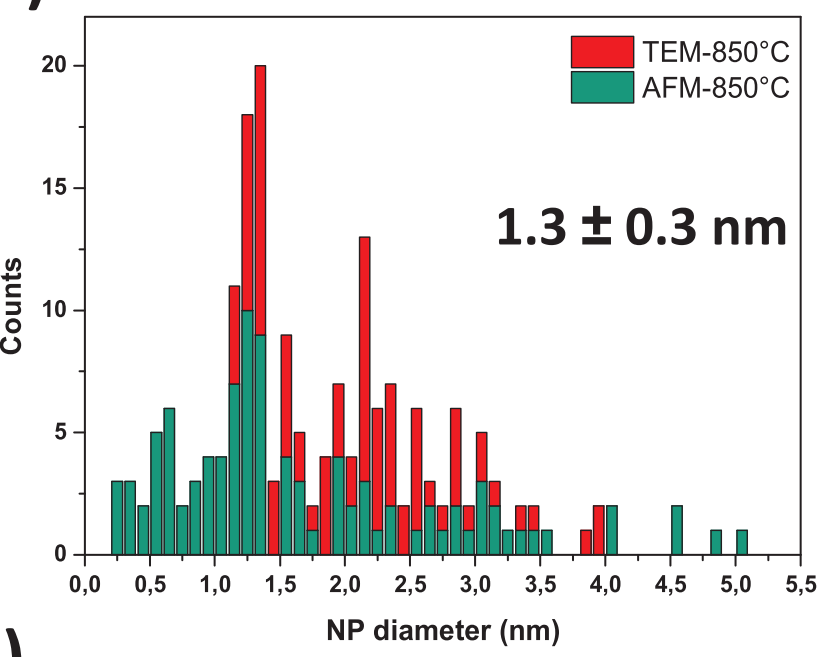

(d)

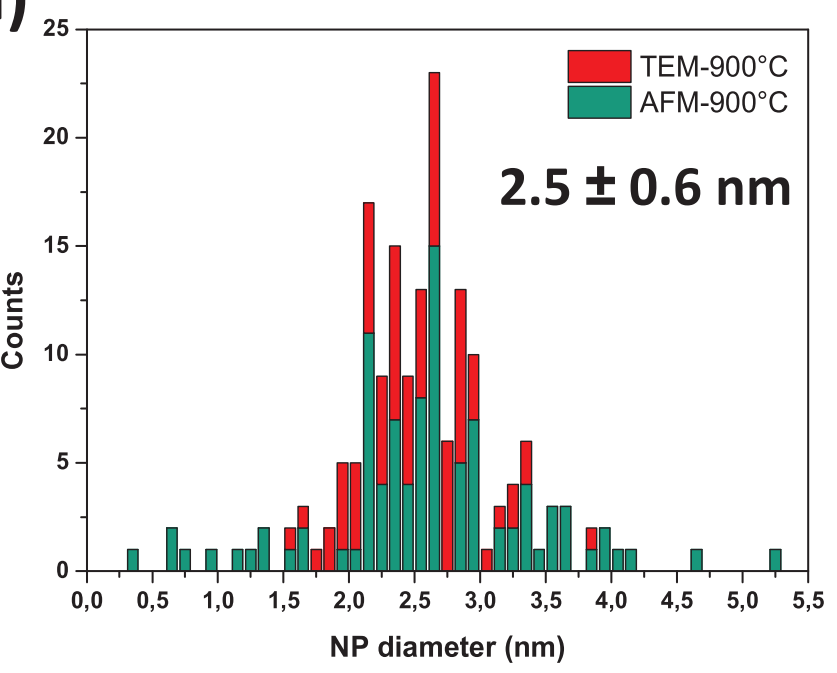

(f)

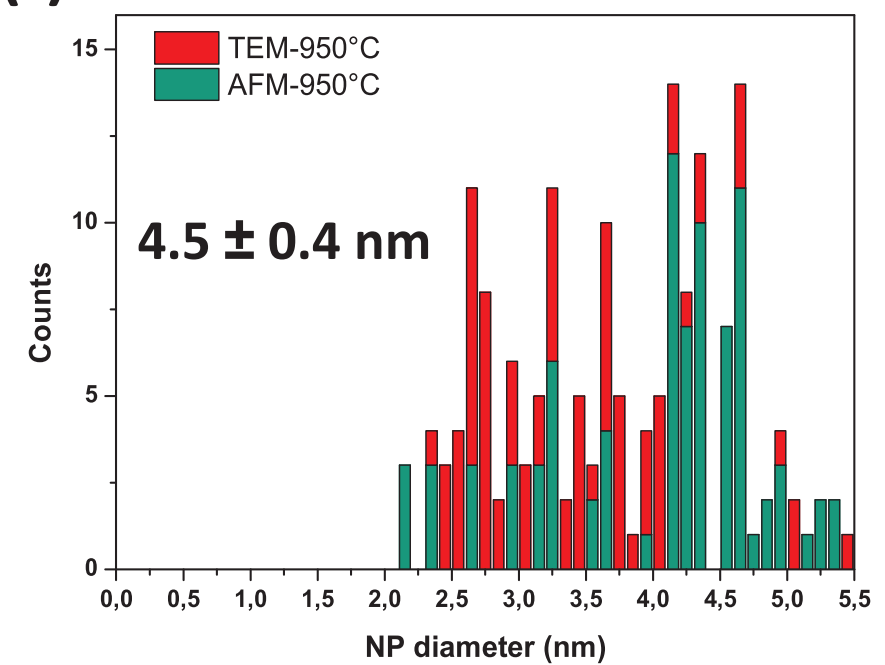

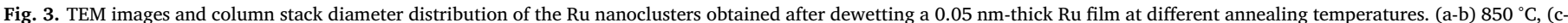
d) $900{ }^{\circ} \mathrm{C}$ and (e-f) $950{ }^{\circ} \mathrm{C}$. 

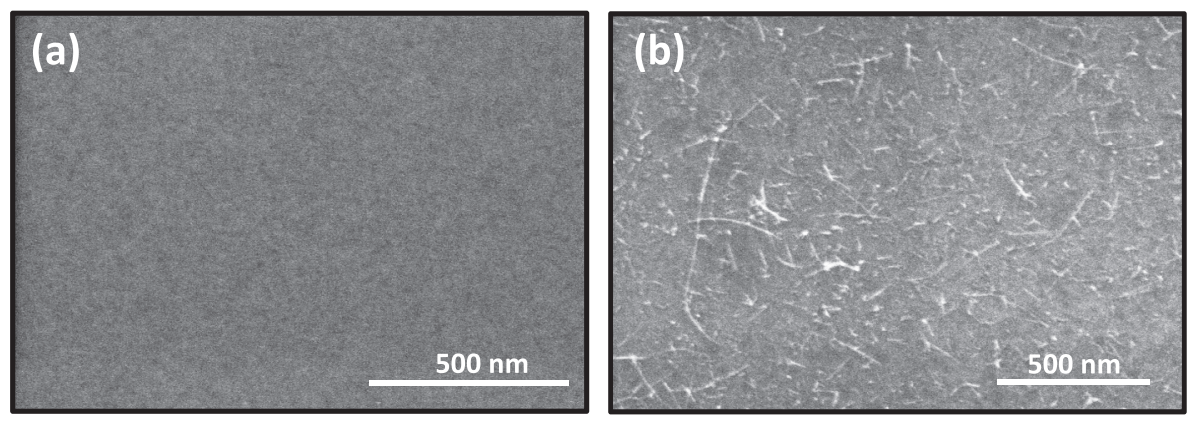

Fig. 4. Scanning electron microscopy (SEM) micrographs on SWCNTs grown from Ru nanoclusters at various temperatures. (a) $800{ }^{\circ} \mathrm{C}$, (b) $850{ }^{\circ} \mathrm{C}$, (c) $900{ }^{\circ} \mathrm{C}$ and (d) $950{ }^{\circ} \mathrm{C}$. The $\mathrm{Ru}$ nanoclusters were first prepared from dewetting $0.05 \mathrm{~nm}$-thick Ru films at $850{ }^{\circ} \mathrm{C}$.
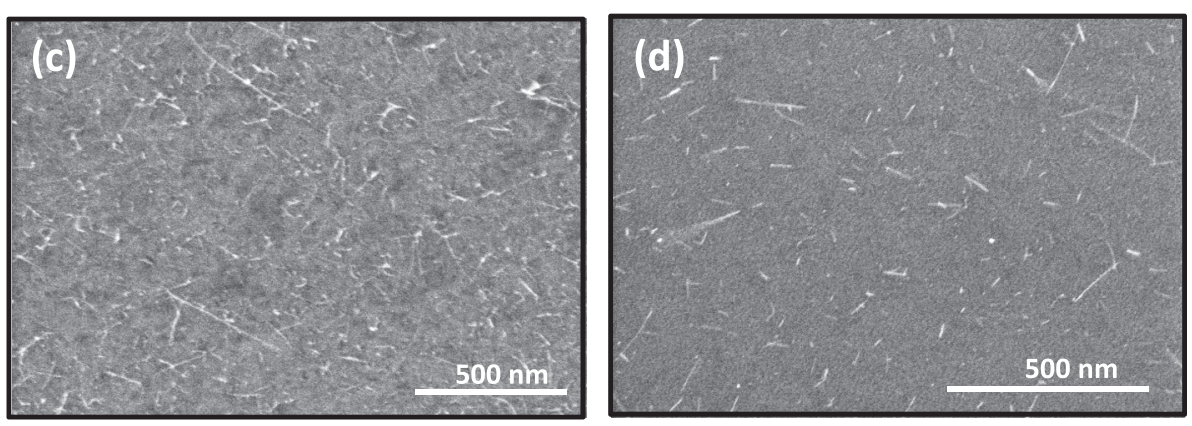

growth temperature was investigated for understanding its impact on the density, the diameter and the electronic character of the as-produced SWCNTs. A strong correlation between the catalyst size and the diameter distribution of as-grown SWCNTs was obtained, as we observed before [13]. Our results provide a promising way for the synthesis of SWCNTs with a precise diameter, by simply adjusting the growth parameters, including catalyst preparation. This controllable synthesis process paves the way for achieving high performance SWCNTs-based devices in future electronics.

\section{Material and methods}

\subsection{Catalyst preparation}

p-type doped Si substrates covered with a $100 \mathrm{~nm}$ thick thermal oxide $\left(\mathrm{SiO}_{2} / \mathrm{Si}\right)$ were used for the growth of SWCNTs. Before catalyst deposition, all substrates were cleaned following a procedure based on Piranha solution $\left(70 \% \mathrm{H}_{2} \mathrm{SO}_{4} / 30 \% \mathrm{H}_{2} \mathrm{O}_{2}\right)$. They were then rinsed ten times with deionized water and dried under nitrogen or argon flow. After cleaning, rinsing and drying, a thin layer of Ru catalyst was deposited on top of the substrates inside a Molecular Beam Epitaxy (MBE) reactor.

\subsection{Synthesis of SWCNTS}

The SWCNT growth process is similar to that reported previously [13]. Briefly, the synthesis was performed using a homemade experimental d-HFCVD set-up system (see Fig. S1 in supporting information). It mainly consists of a horizontal quartz tube enclosed in a cylindrical heater. The quartz tube is connected to methane and hydrogen feed lines on one side and to a pumping system on the other side (the residual base pressure is about $10^{-6}$ mbar). The methane $\left(\mathrm{CH}_{4}\right)$ and hydrogen $\left(\mathrm{H}_{2}\right)$ are injected separately and forced to pass over two separate tungsten filaments $(0.38 \mathrm{~mm}$ in diameter), mounted horizontally near the substrate, and independently electrically driven at a variable power (for filament temperature ranging from $1200{ }^{\circ} \mathrm{C}$ to $2000{ }^{\circ} \mathrm{C}$ ). Prior to SWCNTs growth, the substrates are heated at different temperatures $\left(800{ }^{\circ} \mathrm{C}, 850{ }^{\circ} \mathrm{C}, 900{ }^{\circ} \mathrm{C}\right.$ and $950{ }^{\circ} \mathrm{C}$ ) and exposed for $5 \mathrm{~min}$ to a hotfilament activated ( $160 \mathrm{~W}$ - approximately $2000^{\circ} \mathrm{C}$ measured with an optical pyrometer) hydrogen flow (100 sccm at $90 \mathrm{mbar}$ ) in order to transform the $\mathrm{Ru}$ thin film into a random collection of $\mathrm{Ru}$ nanoclusters (dewetting operation). Atomic hydrogen tends to block surface diffusion by creating defects on the $\mathrm{SiO}_{2}$ surface; those defects pin the nanoparticles and prevents their agglomeration [14]. After this annealing under atomic hydrogen, the substrate is brought to various temperatures and a gas mixture $\mathrm{CH}_{4}: \mathrm{H}_{2}(1: 5)$ is introduced into the reactor to grow SWCNTs for $15 \mathrm{~min}$. In order to efficiently pre-dissociate the $\mathrm{CH}_{4}$ molecules, the methane flow is activated during SWCNTs growth, by heating up the corresponding W filament at $1700{ }^{\circ} \mathrm{C}(120 \mathrm{~W})$. During growth, the hydrogen flow is also activated by heating up the corresponding filament at $2000{ }^{\circ} \mathrm{C}(160 \mathrm{~W}$ - as for the dewetting of the $\mathrm{Ru}$ thin film). The thus generated atomic hydrogen is used to remove the undesired carbon particles and amorphous deposits formed on catalyst seeds, tube walls or substrate surface during C-CVD growth. During the heating, the substrate temperature was monitored by a pyrometer which can measure the sample temperature between 200 and $2000{ }^{\circ} \mathrm{C}$.

\subsection{Characterization techniques}

After dewetting the Ru films, the samples were characterized by Atomic Force Microscopy (AFM), using a VEECO Dimension 3100 instrument and High Resolution Transmission Electron Microscopy (HRTEM) to confirm the catalysts density and morphology. After SWCNTs growth, Raman spectra were recorded using a high-resolution confocal Raman microscope (Labram HR800; HORIBA Jobin Yvon). MicroRaman mapping was performed in high resolution using different laser excitations of $\lambda=473 \mathrm{~nm}, 532 \mathrm{~nm}, 633 \mathrm{~nm}$ and $785 \mathrm{~nm}$. Raman analysis enables the evaluation of the diameter and chirality of the asgrown SWCNTs. Scanning Electron Microscopy (SEM) observations were carried out on a HITACHI S 4800 electron microscope in order to determine the density and the length of the final grown SWCNTs. The HR-TEM analyses were performed using a FEI-Titan electron microscope operating at 60,80 and $300 \mathrm{kV}$ and equipped with a Cs image corrector. For the SWCNTs observations, an operating voltage of $80 \mathrm{kV}$ was used in order to avoid any beam damage. For the TEM observations of the SWCNTs a preliminary step was mandatory, consisting in transferring the SWCNTs from the substrate surface onto Cu-mesh TEM grids. This has been done using a PMMA transfer method [15]. For the identification of the Ru particles, TEM analyses have been performed on cross-section-lamellas prepared using a FIB-Scios dual beam microscope 

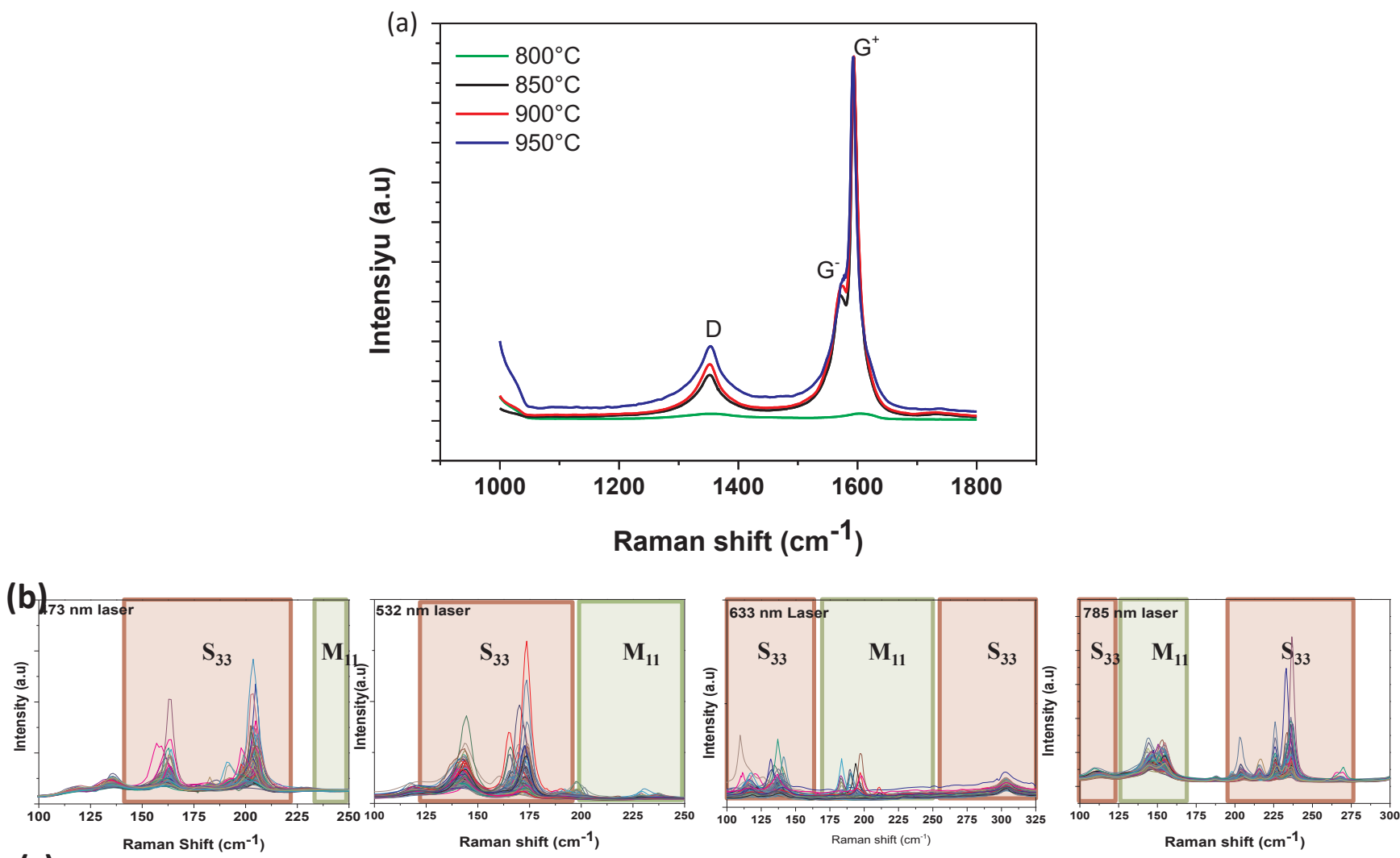

(c)
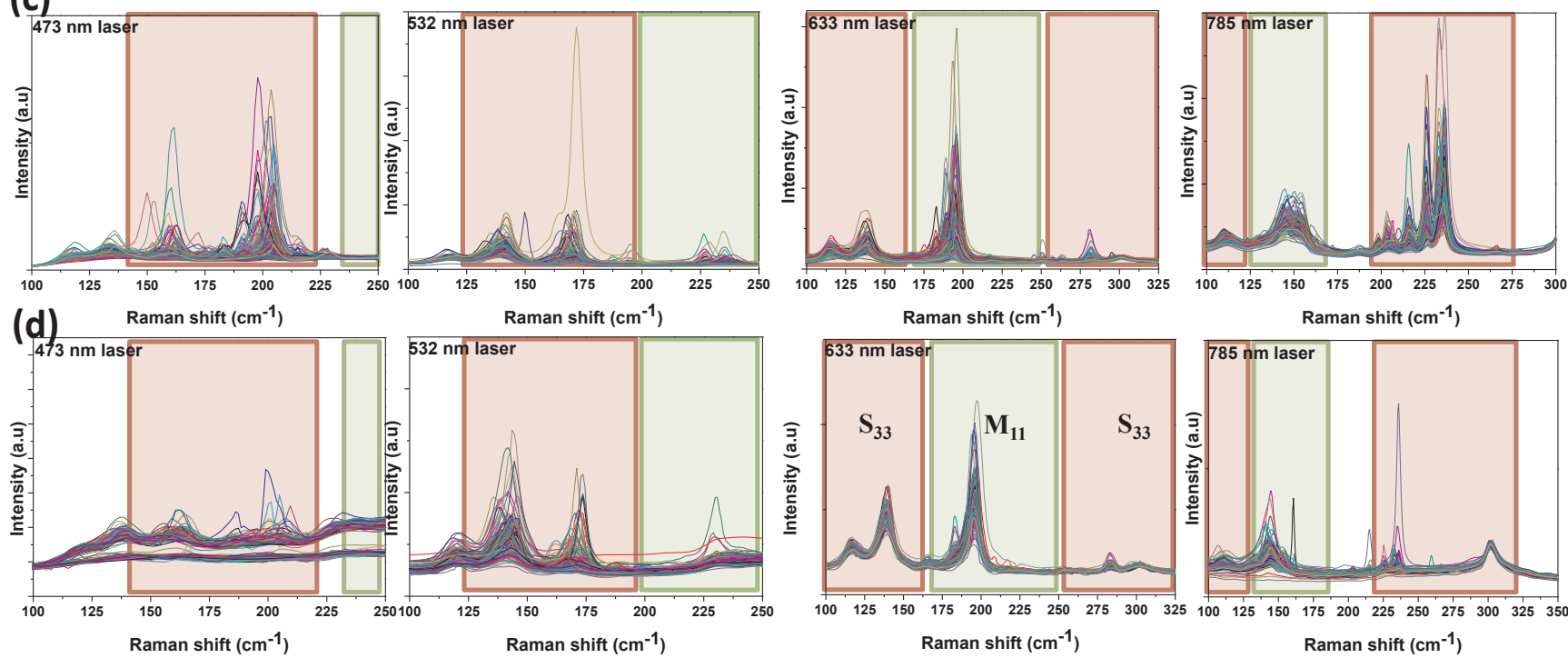

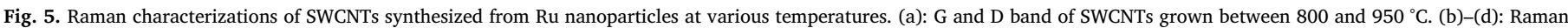

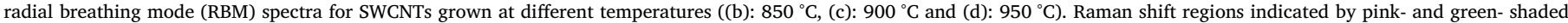

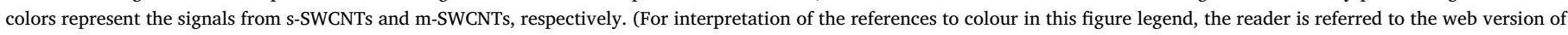
this article.)

$[16,17]$. Further, to investigate their chemical state, energy dispersive $\mathrm{X}$-ray spectrometry (EDX) analyses have been performed on a $200 \mathrm{kV}$ Titan-Themis TEM/STEM electron microscope equipped with a Cs probe corrector and a Chemistem Super-X detector. These two accessories allow chemical mapping of the light and heavy elements with a spatial resolution in the picometer range [18]. The thickness of Ru films after deposition was deduced from Rutherford Backscattering Spectrometry (RBS) analyses. More than three samples were characterized for each growth condition in order to check the reproducibility. Different areas at the edge and the central region of several samples were analyzed and presented similar characteristics.

\section{Results and discussion}

It is now widely accepted that the diameter of the grown SWCNTs depends strongly on the diameter of the catalyst particles they originate from $[19,20]$. So we first investigated the diameter distribution of catalyst NPs obtained after atomic hydrogen $\left(\mathrm{H}_{\mathrm{at}}\right)$ annealing of thin $\mathrm{Ru}$ films at different temperatures and we then studied the correlation between the catalyst particle size and the SWCNTs diameter. The goal of the high temperature annealing $/ \mathrm{H}_{\mathrm{at}}$ treatment is to convert a Ru thin film (monolayer or fraction of a monolayer) into Ru nanoclusters with precise diameters, which then act as catalyst to initiate the growth of 


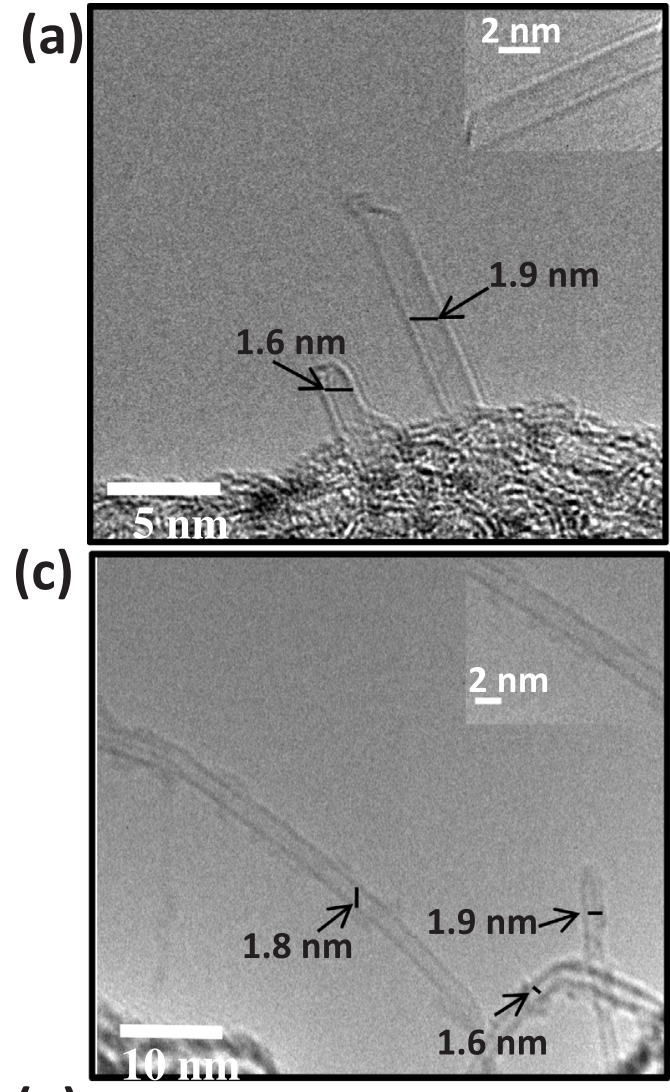

(e)

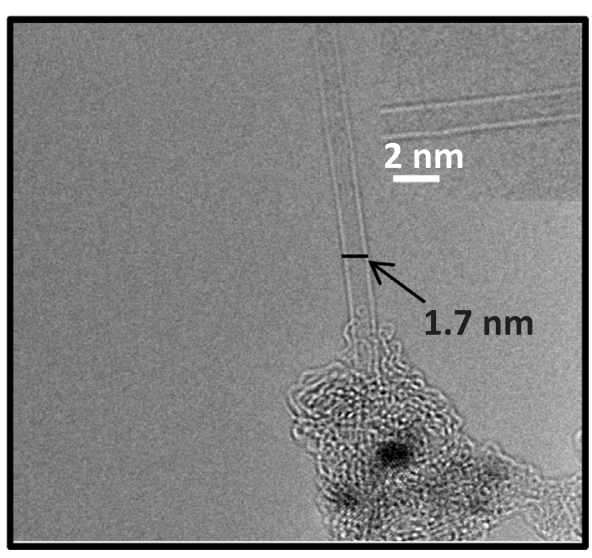

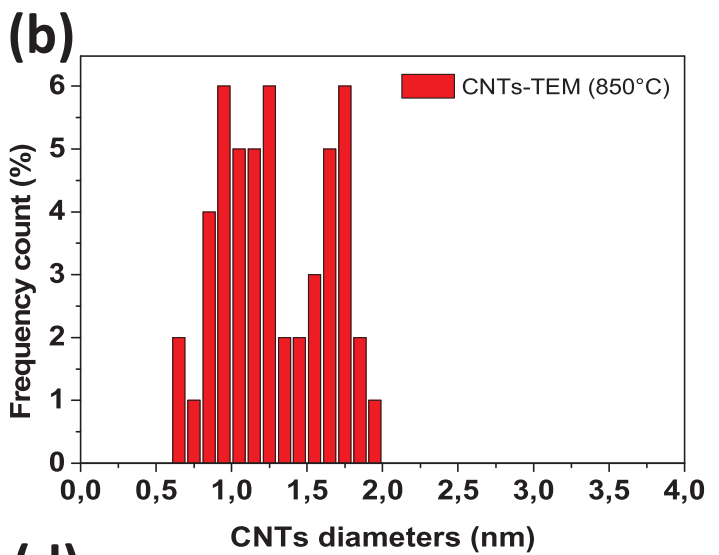

(d)
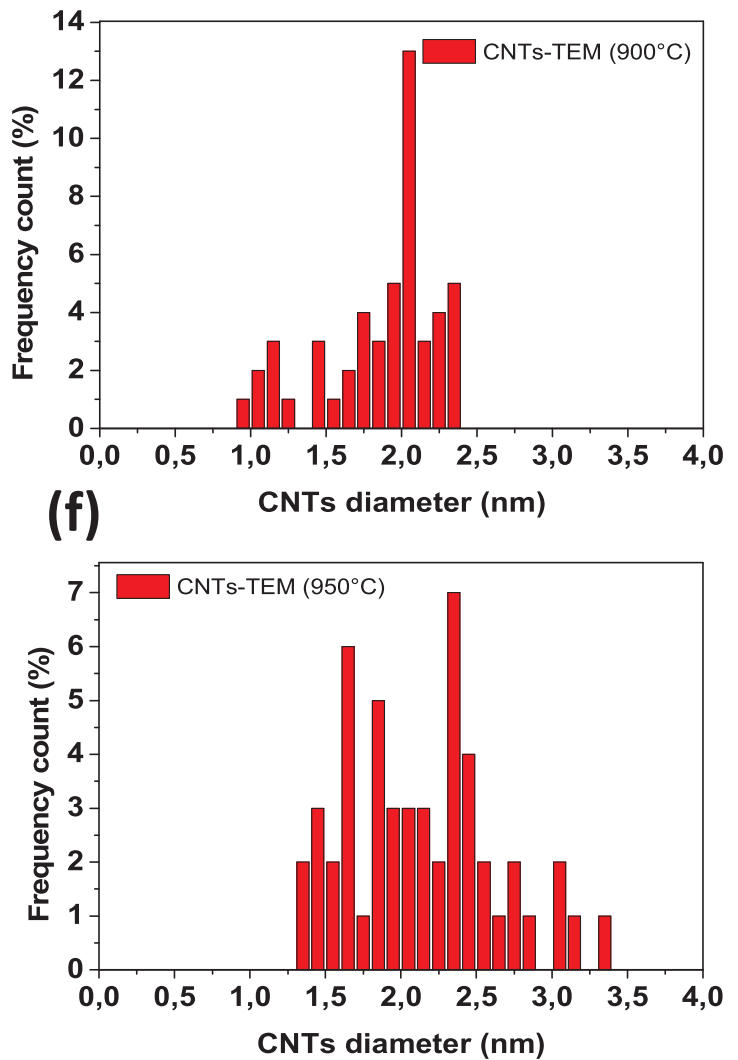

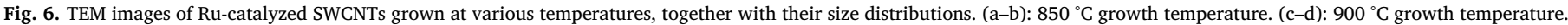
(e-f): $950{ }^{\circ} \mathrm{C}$ growth temperature.

SWCNTs once the methane is introduced into the reactor. We have already reported that the ruthenium catalysts can be active for SWCNTs growth if small nanoparticles (below $3 \mathrm{~nm}$ ) in diameter are used $[13,21]$. Here, we have used Ru films with thicknesses of $0.05 \mathrm{~nm}$, $0.1 \mathrm{~nm}, 0.3 \mathrm{~nm}$ and $0.7 \mathrm{~nm}$. The exact thickness of the Ru layer for each sample was determined from RBS measurements. A more detailed description of the thickness measurement/calculation is given in part B of the supporting information. Fig. S2 in supporting information illustrates the results obtained for a sample for which a $0.05 \mathrm{~nm}$ Ru film thickness had been targeted. Fig. 1(a) shows a TEM micrograph recorded at low magnification on a FIB cross-section lamella prepared after annealing a sample consisting of a $0.05 \mathrm{~nm}$-thick Ru layer at $850{ }^{\circ} \mathrm{C}$ under $\mathrm{H}_{\text {at }}$ during $5 \mathrm{~min}$. Here, we can easily identify the silicon substrate delimited by the yellow dashed line, and the $100 \mathrm{~nm}$ thick $\mathrm{SiO}_{2}$ layer with on top of it the Ru NPs array. This confirms that the thin Ru film has been successfully dewetted and transformed into a uniform dispersion of nanoclusters through the annealing step performed at $850{ }^{\circ} \mathrm{C}$ under $\mathrm{H}_{\mathrm{at}}$. To ensure that the observed nanoparticles were indeed $\mathrm{Ru}$, we recorded the SEM energy dispersive X-ray spectrum (EDX) on a large area on the substrate, see Fig. S3 in supporting information. Additionally Fig. S4(d) gives the EDX spectrum recorded (after dewetting) in conventional TEM mode on the FIB cross-section-lamella prepared on a sample for which a $0.7 \mathrm{~nm}$-thick Ru film was targeted. As it can be seen in Fig. 1(a) the Ru-catalyst NPs formed after annealing present a spherical shape and are well dispersed on the $\mathrm{SiO}_{2}$ surface. From the HR-TEM image represented in Fig. 1(b) one can deduce a diameter size of about 2-4 nm for the Ru NPs annealed under $\mathrm{H}_{\mathrm{at}}$ flow at $850{ }^{\circ} \mathrm{C}$. The Fast Fourier Transform (FFT) evidences the crystalline structure of the catalyst (Fig. 1(c)).

The Ru catalyst presence has been corroborated also by performing STEM - EDX chemical mapping on $\mathrm{Ru} \mathrm{L}_{\alpha}=2.56 \mathrm{eV}$ ionization edge. Fig. 2(b) shows the EDX-relative map obtained by superimposing the 

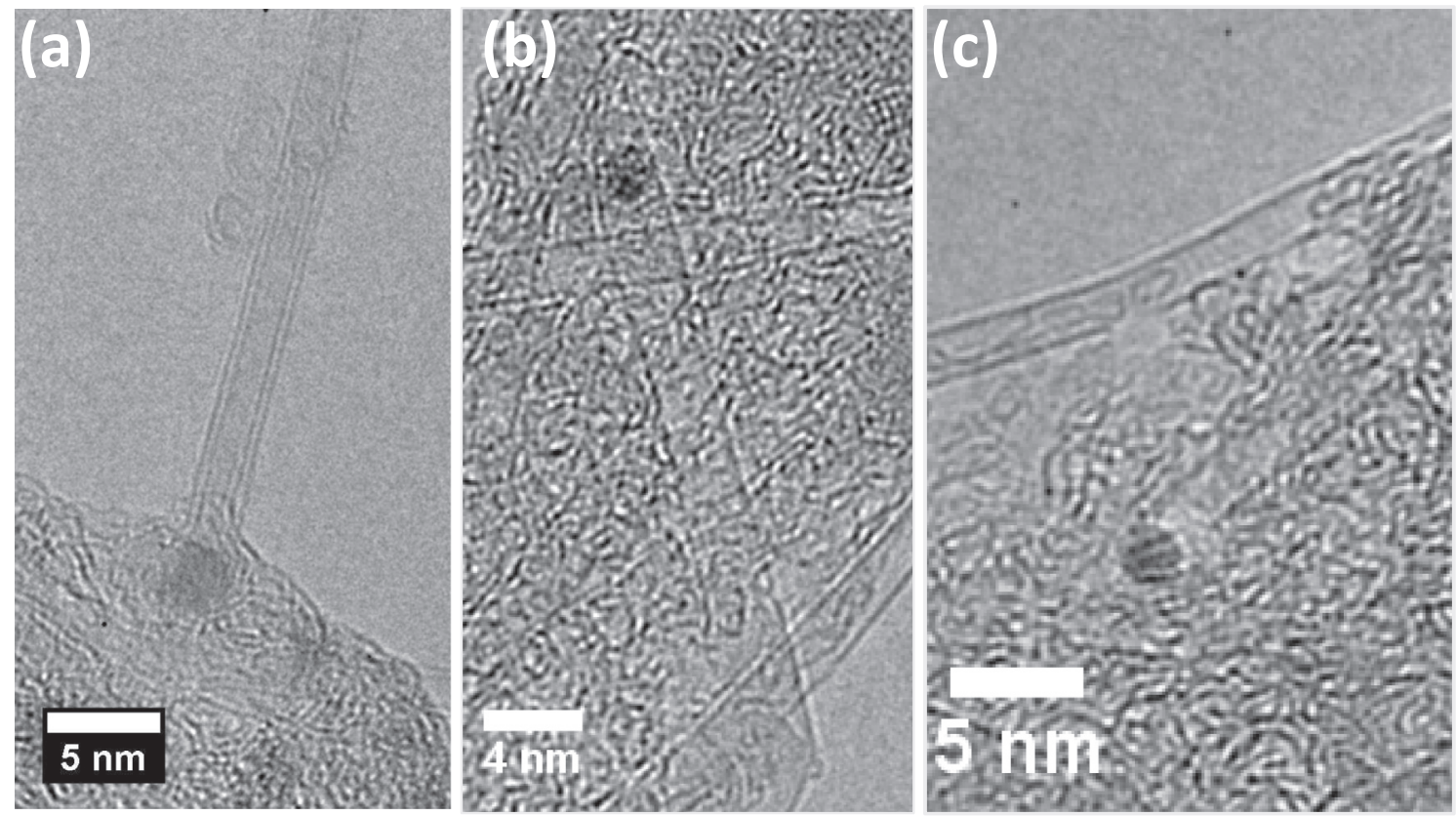

Fig. 7. TEM images on the tube/particle assembly illustrating the growth mode at $850{ }^{\circ} \mathrm{C}$ (a) and $900{ }^{\circ} \mathrm{C}(\mathrm{b}$ and c).

(a)
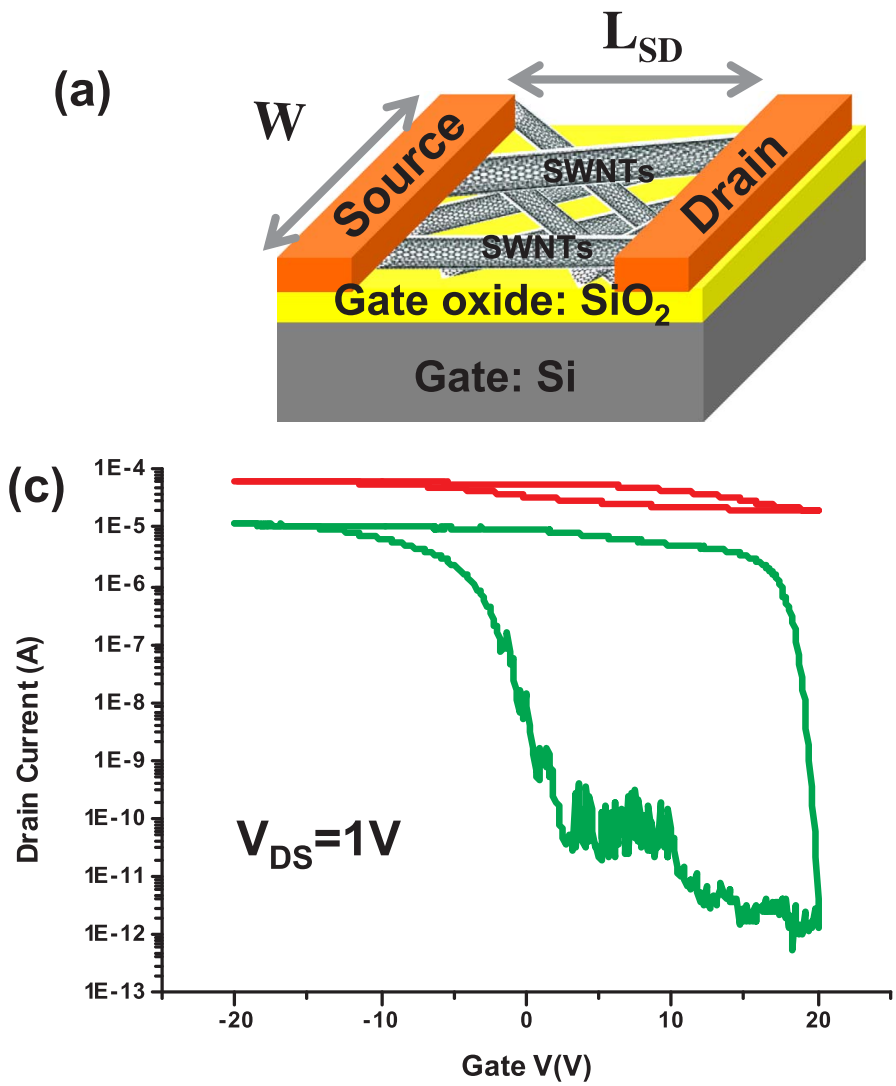

(b)
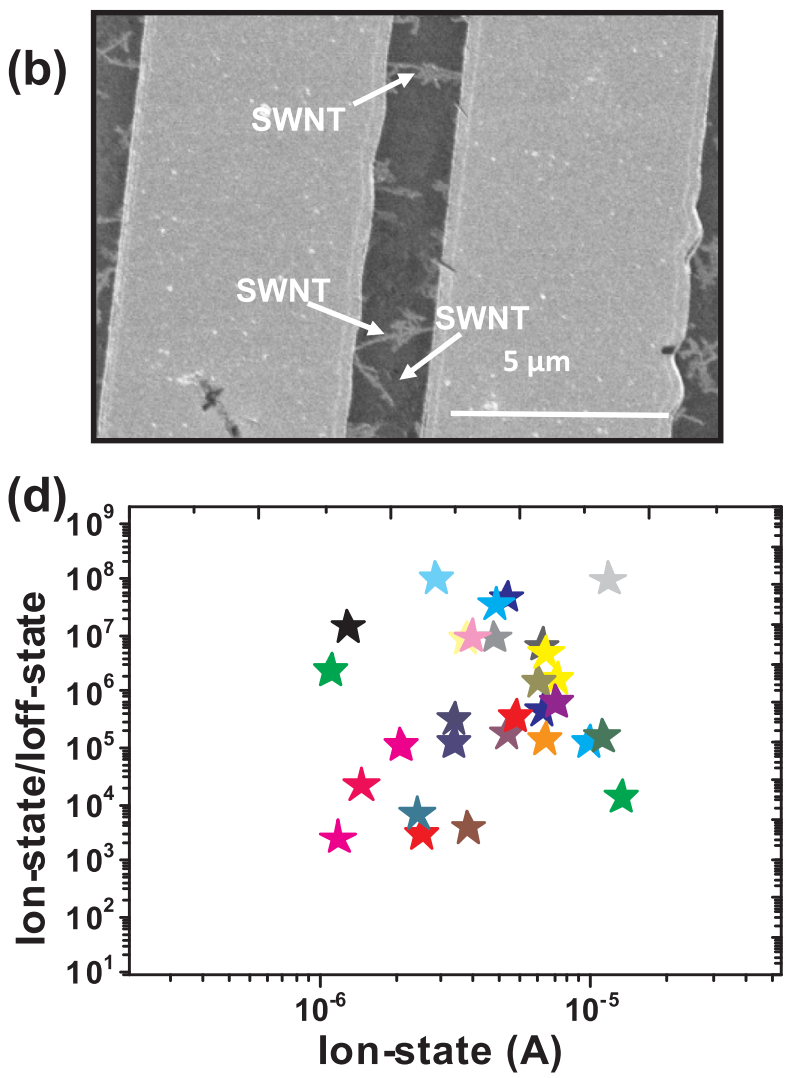

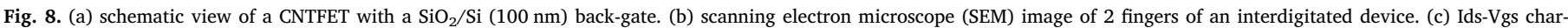
acteristics of CNTFETs before (red curve) and after (green curve) breakdown process. (d) Transfert (Ion/Ioff-Ion) characteristics and the corresponding Ion values.

elemental maps recorded for the Ru La ionization edge (represented in pink color), the carbon $\mathrm{K} \alpha$-ionization edge (represented in red color), and the silicon Ka-ionization edge (represented in dark blue color). The elemental map corresponding to each element within the sample on the same area is given in Fig. S6 in supporting information. Additionally to the study, EDX-line scan analysis recorded locally is given in Fig. 2(c). As it can be observed in Fig. 2(c), the Ru signal across the green line in
Fig. 2(a) is quite low but still detectable compared with the $C$ signal.

In order to get more insights on the catalyst NPs diameter, we measured the diameter distribution of the nanoparticles using both AFM and TEM techniques. We note that the apparent height of the nanoparticles in the AFM data differs from the true particle sizes due to the AFM tip convolution and also to nanoparticles' superposition. The statistical results are shown in Fig. 3. For these experiments, the 
thickness of the Ru films was $0.05 \mathrm{~nm}$. The AFM analyses (given in Fig. S7 in supporting information) and TEM measurements (Fig. 3(a) and (b)) show that the density of Ru nanoclusters is quite uniform after dewetting at $8500^{\circ} \mathrm{C}$, with roughly $78 \%$ of the NP diameter centered at $1.3 \mathrm{~nm}( \pm 0.3 \mathrm{~nm})$ and $22 \%$ centered at $2.2 \mathrm{~nm}$ ( $\pm 0.4 \mathrm{~nm}$ ). Similar measurements were performed on different areas in order to confirm homogeneity over the whole sample. For nanoparticles dewetted at $900{ }^{\circ} \mathrm{C}$, the mean diameter went up to $2.5 \mathrm{~nm}$ with a standard deviation of $0.6 \mathrm{~nm}$ (Fig. 3(c) and (d)). For nanoparticles dewetted at higher temperature $\left(950{ }^{\circ} \mathrm{C}\right)$, the mean diameter increased to $4.5 \mathrm{~nm}$ ( $\pm 0.4 \mathrm{~nm}$ standard deviation, (Fig. 3(e) and (f)) for $52 \%$ of the nanoparticles. To explain this behavior, we suggest that increasing the dewetting temperature favors the catalyst atoms diffusion and nanoparticles formation on the surface of the growth substrate, thus leading to catalyst particles with larger diameter distributions; the Oswald ripening occurrence is characterized by a double size distribution which is apparent only for the distribution $3 \mathrm{~b}$ at $850^{\circ} \mathrm{C}$ and which is achieved at $900{ }^{\circ} \mathrm{C}$. More analysis would be still necessary to ascertain the occurrence of an Ostwald ripening mechanism, which is clearly beyond the scope of this paper. Moreover we believe that the mesh size in size diagrams is a bit too fine. Nevertheless the trend are clearly seen that in turn, lead to broadened diameters distributions of SWCNTs (see below). This shows that the efficiency of $\mathrm{H}_{\mathrm{at}}$ in creating surface defects (that impede surface diffusion) is largely temperature-dependent. We believe that at 900 and $950{ }^{\circ} \mathrm{C}$, the $\mathrm{H}_{\mathrm{at}}$-induced defects are quickly healed.

It was previously reported that a thicker initial metal layer, resulted in a larger SWCNTs diameter and higher density [22,23]. Moreover, from our own experience, large diameter Ru NPs tend to yield metallic SWCNTs $[13,21]$. For these reasons, we have judged that thin initial Ru layers were preferable for the growth of SWCNTs with small diameters, low density and predominantly of semiconducting character. Consequently, we first investigated three small different Ru film thicknesses $(0.05 \mathrm{~nm}, 0.1 \mathrm{~nm}$ and $0.3 \mathrm{~nm})$ for the growth of SWCNTs under the same conditions. The Ru films were first dewetted at $850{ }^{\circ} \mathrm{C}$ for all considered thicknesses. The analysis show high densities of SWCNTs for $0.1 \mathrm{~nm}$ and $0.3 \mathrm{~nm}$-thick Ru films compared to the $0.05 \mathrm{~nm}$-thick one (see Fig. S8 in supporting information). Therefore, since we want low tube densities for a better device fabrication control, we will further consider only the $0.05 \mathrm{~nm}$-thick $\mathrm{Ru}$ films, which is equivalent to a thickness of a fraction of one monolayer.

Since the temperature has a large influence on the diameter distribution of the final SWCNTs arrays [24], we first studied the effect of this parameter. Fig.4(a)-(d) show the scanning electron microscopy (SEM) images of SWCNTs grown at different temperatures using asformed Ru nanoclusters as catalyst precursors (the dewetting temperature was $850^{\circ} \mathrm{C}$ ). We can see from Fig. 4 that practically no SWCNTs were observed at $800^{\circ} \mathrm{C}$ (Fig. 4(a)). When the growth temperature was increased to $850^{\circ} \mathrm{C}$ (Fig. 4(b)), several straight SWCNTs were observed. The yield of SWCNTs synthesis at $900{ }^{\circ} \mathrm{C}$ (Fig. 4(c)) is comparable to that at $850{ }^{\circ} \mathrm{C}$. When the growth temperature was $950{ }^{\circ} \mathrm{C}$ (Fig. 4(d)), both density and average length were slightly reduced. He et al. have recently linked the growth mode (tangential or perpendicular) to the length of SWCNTs after growth [25]; clearly, the perpendicular mode, which occurs on nanoparticles with the larger critical dimension, yields longer tubes. However, our results are obtained with $\mathrm{Ru}$ NPs, whereas those of He et al. are obtained essentially with Ni NPs. At this stage of analysis, we can suggest that at $850{ }^{\circ} \mathrm{C}$ and $900{ }^{\circ} \mathrm{C}$, the growth mode seems to be tangential. Closer TEM analysis have been performed and a detailed discussion regarding the growth mode is given further in the paper. On the contrary, we observe that when the $\mathrm{Ru}$ particles are larger at $950^{\circ} \mathrm{C}$, (see Fig.4c), which should imply essentially a perpendicular growth mode, the corresponding SWCNTs are shorter. In addition to the growth mode, the metal type, its ability to dissolve carbon, as well as its thermodynamic state (solid or partially molten) are certainly important parameters to take into account. For instance, the carbon solubility in Ni determines the "wettability" of the carbon-saturated NP on the graphene layer developing around it, which in turn conditions the proper growth of SWCNTs. Promoting a high wetting angle seems to be a necessary property of a good catalyst for SWCNT growth [26].

We measured the diameter distribution of the SWCNTs using Raman spectroscopy. Fig. 5 shows the Raman spectra corresponding to different SWCNTs growth temperatures. As can be seen in Fig. 5(a), an intense and narrow $G$ band (intensity $I_{G}$ ) is observed (with two components, $\mathrm{G}^{+}$and $\mathrm{G}^{-}$, of the tangential mode vibrations located at 1570 and $1590 \mathrm{~cm}^{-1}$, respectively) whereas the intensity $I_{D}$ of the D band at $\sim 1350 \mathrm{~cm}^{-1}$ (revealing the crystalline disorder and lattice defects) is small for the samples grown between 850 and $950{ }^{\circ} \mathrm{C}$. The $I_{D} / I_{G}$ intensity ratios of SWCNTs synthesized from Ru catalyst precursors at $800,850{ }^{\circ} \mathrm{C}, 900{ }^{\circ} \mathrm{C}$ and $950{ }^{\circ} \mathrm{C}$ are $1.2,0.09,0.1$ and 0.15 , respectively, which suggests a high crystalline quality of the as-grown SWCNTs at different temperatures except $800^{\circ} \mathrm{C}$. Raman spectroscopy can also be used to assign and distinguish between semiconducting and metallic character of SWCNTs, especially when multiple excitation lasers are used [27]. In our experiments, lasers with four different wavelengths $(475,532,633$ and $785 \mathrm{~nm})$ were used to distinguish the semiconducting or metallic character of SWCNTs. As indicated above, the Raman spectra have been measured at three different locations of each substrate (see Fig. S10 in supporting information). The radial breathing modes (RBM) of resonance Raman spectra for SWCNTs grown at different temperatures are shown in Fig. 5(b)-(d). SWCNT diameters were calculated using $d(\mathrm{~nm}) \cong 248 / \omega_{\mathrm{RBM}}\left(\mathrm{cm}^{-1}\right)$, where $d(\mathrm{~nm})$ is the diameter of SWCNTs and $\omega\left(\mathrm{cm}^{-1}\right)$ is the Raman shift [27]. We should mention that no Raman peak was observed at lower Raman shift $\left(<100 \mathrm{~cm}^{-1}\right)$. Combining the Kataura plot and the extracted diameters, the ratio of metallic to semiconducting SWCNTs was determined. In Fig. 5(b-d), Raman shift regions indicated by red- and green-shaded colors denote the signals from s-SWCNTs and m-SWCNTs, respectively. We should note that no RBM peak was observed at $800{ }^{\circ} \mathrm{C}$, probably related to little or no growth [28].

Fig. 5(b) shows a narrow diameter distribution of SWCNTs at $850{ }^{\circ} \mathrm{C}$. When, the growth temperature was increased to $900{ }^{\circ} \mathrm{C}$ a broader size distribution was observed (Fig. 5(c)). This is fully consistent with the increase in diameter size of the NPs that we have observed above. These results are consistent with previous observations [19]. When the growth temperature was further increased to $950{ }^{\circ} \mathrm{C}$, the number of the RBM peaks and the intensity of the peaks were dramatically decreased. These results are in good agreement with the SEM observations (Fig.4(d)) and can be explained by the formation of high density of larger nanoparticles on which nanotube nucleation is more difficult and only small diameter nanoparticles remain active to initiate the growth of SWCNTs $[29,30]$.

We observed from Fig. 5(b and c) that the type selectivity of SWCNTs depends on the synthesis temperature. The type selectivity is calculated by comparing the number of RBM peaks from m-SWCNTs and s-SWCNTs. Thus, by analyzing the peaks corresponding to $\mathrm{m}$ SWCNTs and s- SWCNTs we have found that for SWCNTs synthetized at $850{ }^{\circ} \mathrm{C}$, the $\mathrm{s} /(\mathrm{m}+\mathrm{s})$ ratio is about 0.9 based on the number of the metallic and semiconducting RBM peaks averaged from 150 Raman spectra. On the other hand, for SWCNTs synthesized at $900{ }^{\circ} \mathrm{C}$ and $950{ }^{\circ} \mathrm{C}$, the percentage of s-SWCNTs is about $72 \%$ and $68 \%$ respectively. These observations allow us to conclude that at $850{ }^{\circ} \mathrm{C}$, we obtain a highly selective growth of s-SWCNTs.

The temperature effect on the SWCNTs diameter is further verified by TEM analysis. For a good estimation and in order to analyze as many tubes as possible, SWCNTs were transferred onto the TEM support grids using the PMMA approach [15,31]. The measured diameter distribution of the as-synthesized SWCNTs from TEM analysis is shown in Fig. 6. This analysis has been performed for each considered temperature $\left(850{ }^{\circ} \mathrm{C}, 900^{\circ} \mathrm{C}\right.$ and $950^{\circ} \mathrm{C}$ ). As shown in Fig. $6(\mathrm{~b})$, the mean measured diameter of the SWCNTs grown at $850^{\circ} \mathrm{C}$ is about $1.3 \mathrm{~nm}$ with a 
standard deviation of $0.4 \mathrm{~nm}$. For the SWCNTs grown at $900{ }^{\circ} \mathrm{C}$ and $950{ }^{\circ} \mathrm{C}$, the mean SWCNTs diameter increases to $2.0 \mathrm{~nm}$ (with a standard deviation of $0.4 \mathrm{~nm}$, see Fig. S9 in supporting information) and $2.4 \mathrm{~nm}$ (with a standard deviation of $0.4 \mathrm{~nm}$ ), respectively. We measured altogether 50 tubes on several different samples. We note that the distribution of SWCNTs grown at $850{ }^{\circ} \mathrm{C}$ and $900{ }^{\circ} \mathrm{C}$ is quite uniform, whilst for SWCNTs grown at $950^{\circ} \mathrm{C}$, the diameter distribution of SWCNTs is broader and the presence of a low percentage (about 20\%) of double walled carbon nanotubes (DWCNTs) was also observed (see in set Fig. 6(e)). The above results confirm that we can manipulate the diameter of as-grown SWCNTs by varying the growth temperature. More interestingly, we are able to obtain small diameters with a very narrow distribution.

It is found that the average diameter of the as-produced SWCNTs is smaller than those of the as-formed ruthenium nanoclusters for different temperature, at least before growth. As already quoted above, recently reported results propose that SWCNTs synthesis can follow two nucleation and growth modes: (i) a so-called perpendicular mode which is dominant during the early stage of nanotubes growth [29], stage for which the diameter of SWCNTs is typically independent of the catalyst particle size and (ii) a tangential mode which explains why the diameter of SWCNTs is dependent on the catalyst particle size. This latter mode becomes dominant when the growth conditions are near thermodynamic equilibrium and remain so until growth stops [29]. Having the above in mind, TEM observations have been performed on tube/ particle interface in order to get more insights on the tube growth mode in our situation. Fig. 7 presents TEM images on the tube/particle assembly for which the growth has been performed at two different temperature, namely $850^{\circ} \mathrm{C}$ and $900{ }^{\circ} \mathrm{C}$. If we take into consideration the above definitions of tangential and perpendicular modes [25], in our case, it seems that the growth mode is tangential at 850 and $900{ }^{\circ} \mathrm{C}$, since the particle diameter (after growth) is very close to the tube diameter.

The general approach described here, which consists in using thickness-controlled thin film Ru catalysts, coupled with a high temperature atomic hydrogen treatment, brings the advantage of forming uniform nanoclusters at least at $850{ }^{\circ} \mathrm{C}$. Consequently, SWCNTs with narrow diameter distribution can be obtained.

From all the above, our strategy to obtain small diameter SWCNTs with narrow distribution is a result of two crucial factors. First, using dewetting of thin film Ru catalyst ensures the uniformity of the nanoclusters. Second, the use of atomic hydrogen pre-treatment promotes further control over the diameter distribution of the catalyst by blocking surface diffusion, at least at $850{ }^{\circ} \mathrm{C}$.

Such SWCNTs networks are of great interest since they can behave as semiconducting channels for field effect transistor fabrication. To illustrate this potentiality, interdigitated electrodes made of Pd $(40 \mathrm{~nm})$ were deposited onto as-grown SWCNTs at $850{ }^{\circ} \mathrm{C}$, directly on $\mathrm{SiO}_{2} / \mathrm{Si}$ substrate following a previously reported method (see Fig. S11 in supporting information) [13]. The as-grown SWCNTs exhibit lengths in the range of $\sim 0.4-3.8 \mu \mathrm{m}$ (the statistical length distributions of asgrown SWCNTs are presented in supporting information, Fig. S12) and the CNTs densities are about $40-45 / \mu \mathrm{m}^{2}$ (Fig. 8(b)). Typical transfer characteristics of such bottom gate devices (with channel length and width of respectively $\mathrm{L}=2 \mu \mathrm{m}$ and $\mathrm{W}=2 \mathrm{~mm}$ ) are displayed in Fig. 8c. As-grown SWCNT networks exhibits typical p-type response with low "on" and "off" current (Ion/Ioff) ratio of about one decade but relatively high "on" current (Ion $=10^{-5} \mathrm{~A}$ ) (Fig. $8 \mathrm{c}$ red curve). This modest performance is explained by the presence of a few metallic nanotubes in the network [27]. In order to improve the Ion/Ioff ratio, we selectively "burned" the metallic paths by increasing $V_{D S}$ up to $40 \mathrm{~V}$ while keeping the device in "off" state $\left(\mathrm{V}_{\mathrm{G}}=20 \mathrm{~V}\right)$ ("breakdown process" described in [32]). After such a procedure, a decrease of the Ion current is observed (see Fig. 8c (green curve)) and a dramatic increase of Ion/Ioff ratio up to 7 decades for the channel length $\left(\mathrm{L}_{\mathrm{SD}}\right)$ of $2 \mu \mathrm{m}$. The carrier mobility calculated for those semiconductor-rich SWCNTs
FET is $\sim 10-15 \mathrm{~cm}^{2} / \mathrm{Vs}$, as evaluated by the standard MOS formula [33]. We note that the mobility value we obtain here is quite modest, particularly when compared with our former work [13]; we suspect some contact problems in our FETs. Furthermore, we measured a series of transport characteristics of 30 devices possessing the same channel length and prepared under the same condition (see Fig. S13 in supporting information). Fig. 8d presents the plot of the on-currents vs on/ off ratios. This figure clearly shows that some FETs do not comprise any metallic specimen (Ion/Ioff $>10^{6}$ ) thus confirming the high proportion of semiconducting specimens in our as grown SWCNTs.

\section{Conclusion}

In summary, we have carefully studied the C-CVD synthesis of SWCNTs using Ru catalyst nanoparticles. Those nanoparticles resulted from the controlled dewetting of thin Ru films deposited by MBE. We have shown by statistical AFM, TEM and Raman analysis that the size distribution of $\mathrm{Ru}$ catalysts and thus nanotubes diameters strongly depended on the temperature. SWCNTs with high crystalline quality and with a narrow diameter distribution were synthesized at the optimal temperature of $850^{\circ} \mathrm{C}$. It was found that a high content ( $\left.~ 90 \%\right)$ of $s$ SWCNTs was obtained. The TFTs fabricated using these s-SWCNTs showed good electrical performance, with on-state current around $10^{-8} \mathrm{~A} / \mu \mathrm{m}$ of gate width, combined with $I_{O N} / I_{O F F}$ current ratios over $10^{7}$.

\section{Acknowledgements}

This work received support from the French state managed by the National Research Agency under the Investments for the program under the reference, ANR-13-BS10-0015-01 (SYNAPSE project), ANR-10EQPX-0048, ANR-10-EQPX-50-Tempos pole-NanoTEM, and poleNanoMax. The authors would also like to acknowledge Chaire "André Citroen" for financial support. Dr. J. Arabski (IPCMS-GMM, Strasbourg) and Dr. C. Speisser (ICube-MaCEPV, Strasbourg) are acknowledged for MBE depositions. Dr. C. Bichara (CINAM, Marseille) and Dr. H. Amara (ONERA, Châtillon) are acknowledged for helpful discussions.

\section{Appendix A. Supplementary data}

Supplementary data associated with this article can be found, in the online version, at http://dx.doi.org/10.1016/j.cej.2017.09.073.

\section{References}

[1] A. Javey, J. Guo, Q. Wang, M. Lundstrom, H. Dai, Ballistic carbon nanotube fieldeffect transistors, Nature 424 (2003) 654-657.

[2] R.H. Baughman, A.A. Zakhidov, W.A. de Heer, Carbon nanotubes-the route toward applications, Science 297 (2002) 787-792.

[3] N. Rouhi, D. Jain, P.J. Burke, High-performance semiconducting nanotube inks: progress and prospects, ACS Nano 5 (2011) 8471-8487.

[4] H. Dai, Carbon nanotubes: synthesis, integration, and properties, Acc. Chem. Res. 35 (2002) 1035-1044.

[5] H. Dai, Nanotube growth and characterization, Carbon Nanotubes, Springer Berlin, Berlin, 2001, pp. 29-53.

[6] J. Kong, H. Soh, A. Cassell, C.F. Quate, H. Dai, Synthesis of individual single-walled carbon nanotubes on patterned silicon wafers, Nature 395 (1998) 878-881.

[7] Q. Zhang, J.Q. Huang, M.Q. Zhao, W.Z. Qian, F. Wei, Carbon nanotube mass production: principles and processes, ChemSusChem 4 (2011) 864-889.

[8] J. Kong, A.M. Cassell, H. Dai, Chemical vapor deposition of methane for singlewalled carbon nanotubes, Chem. Phys. Lett. 292 (1998) 567-574.

[9] F. Yang, X. Wang, D. Zhang, J. Yang, D. Luo, Z. Xu, J. Wei, J.Q. Wang, Z. Xu, F. Peng, X. Li, R. Li, Y. Li, M. Li, X. Bai, F. Ding, Y. Li, Chirality-specific growth of single-walled carbon nanotubes on solid alloy catalysts, Nature 510 (2014) $522-524$.

[10] W.H. Chiang, R.M. Sankaran, Linking catalyst composition to chirality distributions of as-grown single-walled carbon nanotubes by tuning NixFe1 $-\mathrm{x}$ nanoparticles, Nat. Mater. 8 (2009) 882-886.

[11] J. Kong, H. Soh, A. Cassell, C.F. Quate, H. Dai, Self-aligned ballistic molecular transistors and electrically parallel nanotube arrays, Nature 395 (1998) 878-881.

[12] M. Schweiger, M. Schaudig, F. Gannott, M.S. Killian, E. Bitzek, P. Schmuki, et al., Controlling the diameter of aligned single-walled carbon nanotubes on quartz via 
catalyst reduction time, Carbon 95 (2015) 452-459.

[13] F.Z. Bouanis, C.S. Cojocaru, V. Huc, E. Norman, M. Chaigneau, J.L. Maurice, et al., Direct synthesis and integration of individual, diameter-controlled single-walled nanotubes (SWNTs), Chem. Mater. 26 (2014) 5074-5082.

[14] H.J. Jeong, L. Eude, M. Gowtham, B. Marquardt, S.H. Lim, S. Enouz, et al., Atomic hydrogen-driven size control of catalytic nanoparticles for single-walled carbon nanotube growth, Nano 3 (2008) 145-153.

[15] L. Jiao, B. Fan, X. Xian, Z. Wu, J. Zhang, Z. Liu, Creation of nanostructures with poly (methylmethacrylate)-mediated nanotransfer printing, J. Am. Chem. Soc. 130 (2008) 12612-12613.

[16] P. Gasser, U.E. Klotz, F.A. Khalid, Site-specific specimen preparation by focused ion beam milling for transmission electron microscopy of metalmatrix composites, Microscopy Microanal. 10 (2004) 3116316.

[17] N.D. Bassim, B.T. De Gregorio, A.L.D. Kilcoyne, K. Scott, T. Chou, S. Wirick, et al, Minimizing damage during FIB sample preparation of soft materials, J. Microsc. 245 (2012) 288-301.

[18] L. Loisel, I. Florea, C.S. Cojocaru, B. Kang Tay, B. Lebental, Oxidation-based continuous laser writing in vertical nano-crystalline graphite thin films, Sci. Rep. 6 (2016) 26224.

[19] Y. Li, W. Kim, Y. Zhang, M. Rolandi, D. Wang, H. Dai, Growth of single walled carbon nanotubes from discrete catalytic nanoparticles of various sizes, J. Phys. Chem. B 105 (2001) 11424-11431.

[20] H.C. Choi, W. Kim, D. Wang, H. Dai, Delivery of catalytic metal species onto surfaces with dendrimer carriers for the synthesis of carbon nanotubes with narrow diameter distribution, J. Phys. Chem. B 106 (2002) 12361-12365.

[21] F.Z. Bouanis, L. Baraton, V. Huc, D. Pribat, C.S. Cojocaru, High-quality singlewalled carbon nanotubes synthesis by hot filament CVD on Ru nanoparticle catalyst, Thin Solid Films 519 (2011) 4594-4597.

[22] S.K. Youn, N. Yazdani, J. Patscheider, H.G. Park, Facile diameter control of vertically aligned narrow single walled carbon nanotubes, RSC Adv. 3 (2013) 1434-1441.

[23] Y.Y. Wei, G. Eres, V.I. Merkulov, D.H. Lowndes, effect of catalyst film thickness on carbon nanotube growth by selective area chemical vapour deposition, Appl. Phys. Lett. 78 (2001) 1394-1396.

[24] S. Bandow, S. Asaka, Effect of the growth temperature on the diameter distribution and chirality of single walled carbon nanotubes, Phys. Rev. Lett. 80 (1998) 3779-3782.

[25] M. He, Y. Magnin, H. Amara, H. Jiang, H. Cui, F. Fossard, A. Castan, E. Kauppinen, A. Loiseau, C. Bichara, Linking growth mode to lengths of single-walled carbon nanotubes, Carbon 113 (2017) 231-236.

[26] M. Diarra, A. Zappelli, H. Amara, F. Ducastelle, C. Bichara, Importance of carbon solubility and wetting properties of nickel nanoparticles for single wall nanotube growth, Phys. Rev. Lett. 109 (2012) 185501.

[27] M.S. Dresselhaus, G. Dresselhausb, R. Saito, A. Jorio, Raman spectroscopy of carbon nanotubes, Phys. Rep. 409 (2005) 47-99.

[28] A.H. Jayatissa, K. Guo, synthesis of carbon nanotubes at low temperature by filament assisted atmospheric CVD and their field emission characteristics, Vacuum 83 (2009) 853-856.

[29] M.-F.C. Fiawoo, A.-M. Bonnot, H. Amara, C. Bichara, J.T. Pe'nisson, A. Loiseau, Evidence of correlation between catalyst particles and the single-wall carbon nanotube diameter: a first step towards chirality control, Phys. Rev. Lett. 108 (2012) 195503.

[30] H. Dai, A.G. Rinzler, P. Nikolaev, A. Thess, D.T. Colbert, R.E. Smalley, Single-wall nanotubes produced by metal-catalyzed disproportionation of carbon monoxide, Chem. Phys. Lett. 260 (1996) 471-475.

[31] M.H. Rümmeli, C. Kramberger, F. Schäffel, E. Borowiak-Palen, T. Gemming, B. Rellinghaus, et al., Catalyst size dependencies for carbon nanotube synthesis, Phys. Stat. Sol. (b) 244 (2007) 3911-3915.

[32] P.G. Collins, M.S. Arnold, P. Avouris, Engineering carbon nanotubes and nanotube circuits using electrical breakdown, Science 292 (2001) 706-709.

[33] D.M. Sun, M.Y. Timmermans, Y. Tian, A.G. Nasibulin, E.I. Kauppinen, S. Kishimoto, et al., Flexible high-performance carbon nanotube integrated circuits, Nat. Nanotechnol. 6 (2011) 156-161. 